\title{
Ultra-rapid photocatalytic activity of Azadirachta indica engineered colloidal titanium dioxide nanoparticles
}

\author{
Renu Sankar • Kadarmohideen Rizwana • \\ Kanchi Subramanian Shivashangari • \\ Vilwanathan Ravikumar
}

Received: 8 October 2014/ Accepted: 9 October 2014/Published online: 9 November 2014

(C) The Author(s) 2014. This article is published with open access at Springerlink.com

\begin{abstract}
Titanium dioxide nanoparticles were effectively synthesized from aqueous leaf extract of Azadirachta indica under $\mathrm{pH}$ and temperature-dependent condition. $5 \mathrm{mM}$ titanium isopropoxide solution worked as a primary source for the synthesis of titanium dioxide nanoparticles. The green synthesized titanium dioxide nanoparticles were confirmed by UV-Vis spectroscopy. Fourier transform infrared spectrum of synthesized titanium dioxide nanoparticles authorized the presence of bioactive compounds in the leaf extract, which may play a role as capping and reducing agent. The high-resolution scanning electron microscopy and dynamic light scattering analyses results showed the interconnected spherical in shape titanium dioxide nanoparticles having a mean particle size of $124 \mathrm{~nm}$ and a zeta potential of $-24 \mathrm{mV}$. Besides, the colloidal titanium dioxide nanoparticles energetically degrade the industrially harmful methyl red dye under bright sunlight.
\end{abstract}

Keywords Green synthesis - Azadirachta indica . Titanium dioxide nanoparticles $\cdot$ FT-IR $\cdot$ Photocatalytic activity

R. Sankar · K. Rizwana · V. Ravikumar $(\varangle)$

Department of Biochemistry, School of Life Sciences,

Bharathidasan University, Tiruchirappalli 620024 ,

Tamilnadu, India

e-mail: ravikumarbdu@gmail.com

K. S. Shivashangari

Regional Forensic Science Laboratory, Tiruchirappalli,

Tamilnadu, India

K. S. Shivashangari ( $\square$ )

No-75, Second Street, Ashok Nagar, Kanchipuram 631 502,

Tamilnadu, India

e-mail: shivashangari@gmail.com

\section{Introduction}

At this instant, nanotechnology deals with the most advanced applications in a variety of fields including mechanical, electronics, imaging, targeted delivery and molecular diagnosis, since of their size, shape-dependent physical and chemical properties (Kumar et al. 2012; Syed and Ahmad 2013). Now metal and metal oxide nanoparticles got widespread attraction because of their latent demands in nanoscience and nanotechnology field (Sankar et al. 2014a, b, c). Moreover, metal nanoparticles have surface plasmon resonance absorption (SPR). This SPR arises from the coherent existence of free electrons in the conduction band due to the small particle size. Among abundant metal oxide nanoparticles, semi-conductive titanium dioxide nanoparticles have apprehensive interest due to their distinctive properties and numerous potential technological applications such as ability to decompose chemical compounds, act as a biosensor, photocatalysis, memory devices, solar cell sensors, super hydrophilic and antibacterial properties (Tayade et al. 2007).

Variety of different color dyes are used in many industries for their exclusive products such as cosmetics, textile, paper and plastics (Sankar et al. 2014b). In environmental concern, color dyes are bio-recalcitrance, potential toxicity and carcinogenicity in animals and human beings. We believe as a truth that the color dyes when integrated into our body react with enzymes and can cause many diseases like cancer, liver and kidney damage (Daneshvar et al. 2003). Certain azo dyes that include methyl red have been proved to be highly toxic, mutagenic and carcinogenic in nature. The elimination of these dyes from the environment is a critical ecological problem (Kumar et al. 2013). The industries eradicate large volume of colored effluents, which are mostly toxic and tough to 
destruction by currently available treatment methods. Hence, we are into cutting-edge stage to find an alternative method to remove textile color dyes. Photocatalytic degradation by way of metal nanoparticles is a new, real and fast technique for the removal of color dyes (Habibi et al. 2001). In newly, plant leaf extract mediated metal nanoparticles spectacles safe and ecofriendly biological approaches (Sankar et al. 2013; Sulaiman et al. 2013). In the present study, we take an effort to synthesize Azadirachta indica ( $A$. indica) leaf-extract-mediated titanium dioxide nanoparticles and evaluate their photocatalytic degradation property against methyl red color dye.

\section{Materials and methods}

Green synthesis of titanium dioxide nanoparticles

The undamaged healthy A. indica leaves were collected. The collected leaves were washed with deionized water, shadow dried for 2-3 weeks and then powdered using mixer grinder. For the preparation of aqueous leaf extract (ALE) solution, $10 \mathrm{~g}$ of powder dissolved in $100 \mathrm{ml}$ of deionized water, boiled at $60{ }^{\circ} \mathrm{C}$ for $10 \mathrm{~min}$ to kill the pathogens in ALE solution. After cooling, ALE solution was filtered using Whatman No.1 filter paper. For the synthesis of titanium dioxide nanoparticles, $10 \mathrm{ml}$ of filtered ALE solution was added to $90 \mathrm{ml}$ of $5 \mathrm{mM}$ titanium isopropoxide solution $(\mathrm{pH}$ 1.5) in an Erlenmeyer flask under stirring at $50{ }^{\circ} \mathrm{C}$. After $5 \mathrm{~h}$, the developed dark brown color confirmed titanium dioxide nanoparticles formation (Sankar et al. 2014a).

Characterization of titanium dioxide nanoparticles

The green synthesized titanium dioxide nanoparticles were confirmed using UV-visible double-beam spectrophotometer (UV-1601, Shimadzu, Japan). Fourier transform infrared spectroscopy (FT-IR) spectrum was achieved by spectrum RX-1 instrument in diffuse reflectance mode functioned at a resolution of $4 \mathrm{~cm}^{-1}$. The field emission scanning electron microscope (FE-SEM) Carl Zeiss,
Fig. 1 a UV-Vis spectra of colloidal titanium dioxide nanoparticles synthesized using Azadirachta indica; b Fourier transform infrared spectra of titanium dioxide nanoparticles (a)

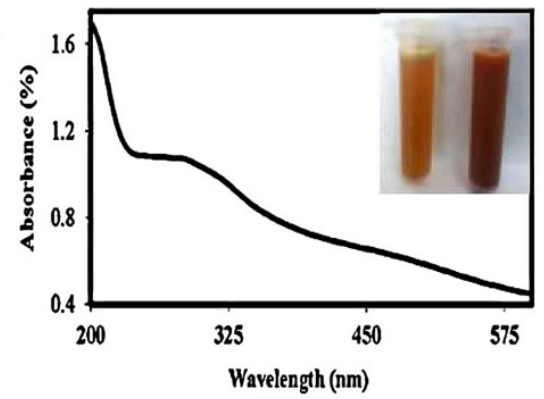

(b)

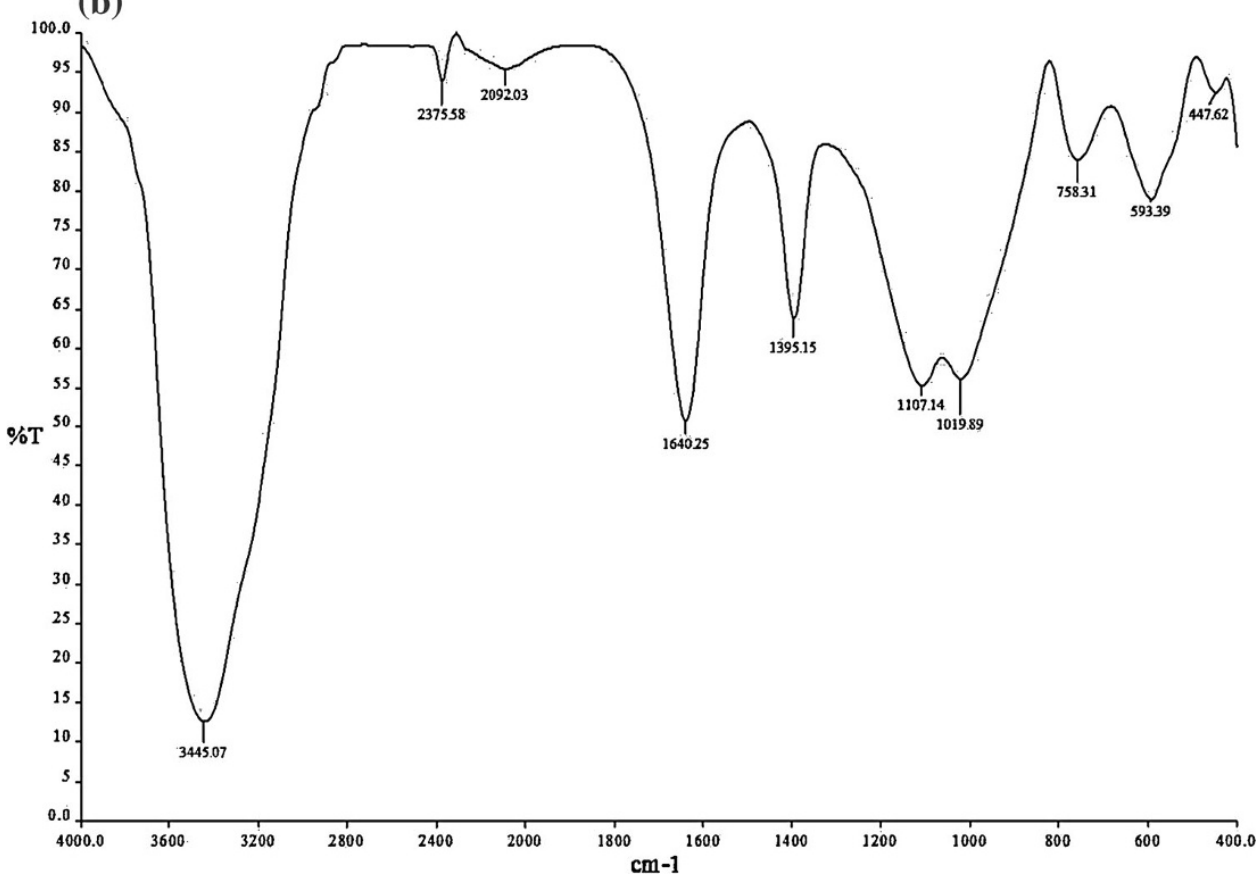


SIGMA instrument (UK) is used to realize the morphology images of the synthesized nanoparticles. Malvern Zetazier (Nano ZS90, UK) instrument was used to find out the stability and particle size distribution of titanium dioxide nanoparticles. X-Ray diffraction (XRD) pattern of titanium dioxide nanoparticles was achieved using powder X-ray diffractometer (Philips X'Pert Pro X-ray diffractometer).

Photocatalytic activity

The photocatalytic degradation of methyl red (Hi media, India) was performed by green synthesized titanium dioxide nanoparticles. To acquire the equilibrium of methyl red [50\% (v/v) in distilled water] dye, the solution was continuously stirred for $30 \mathrm{~min}$. In brief, $10 \mathrm{mg}$ of titanium dioxide nanoparticles was added in $50 \mathrm{ml}$ of methyl red dye solution and stirred constantly. In our photocatalytic degradation experiment, bright sunlight acts as a major light source. At different time intervals, the collected samples were centrifuged at $12,000 \mathrm{rpm}$ for $15 \mathrm{~min}$. The absorbance spectrum of the supernatant was consequently measured using a spectrophotometer (Shimadzu-UV-1601) (Sankar et al. 2014b).

\section{Results and discussion}

Green chemistry mediated synthesis of metal and metal oxide nanoparticles have an endless application in a variety
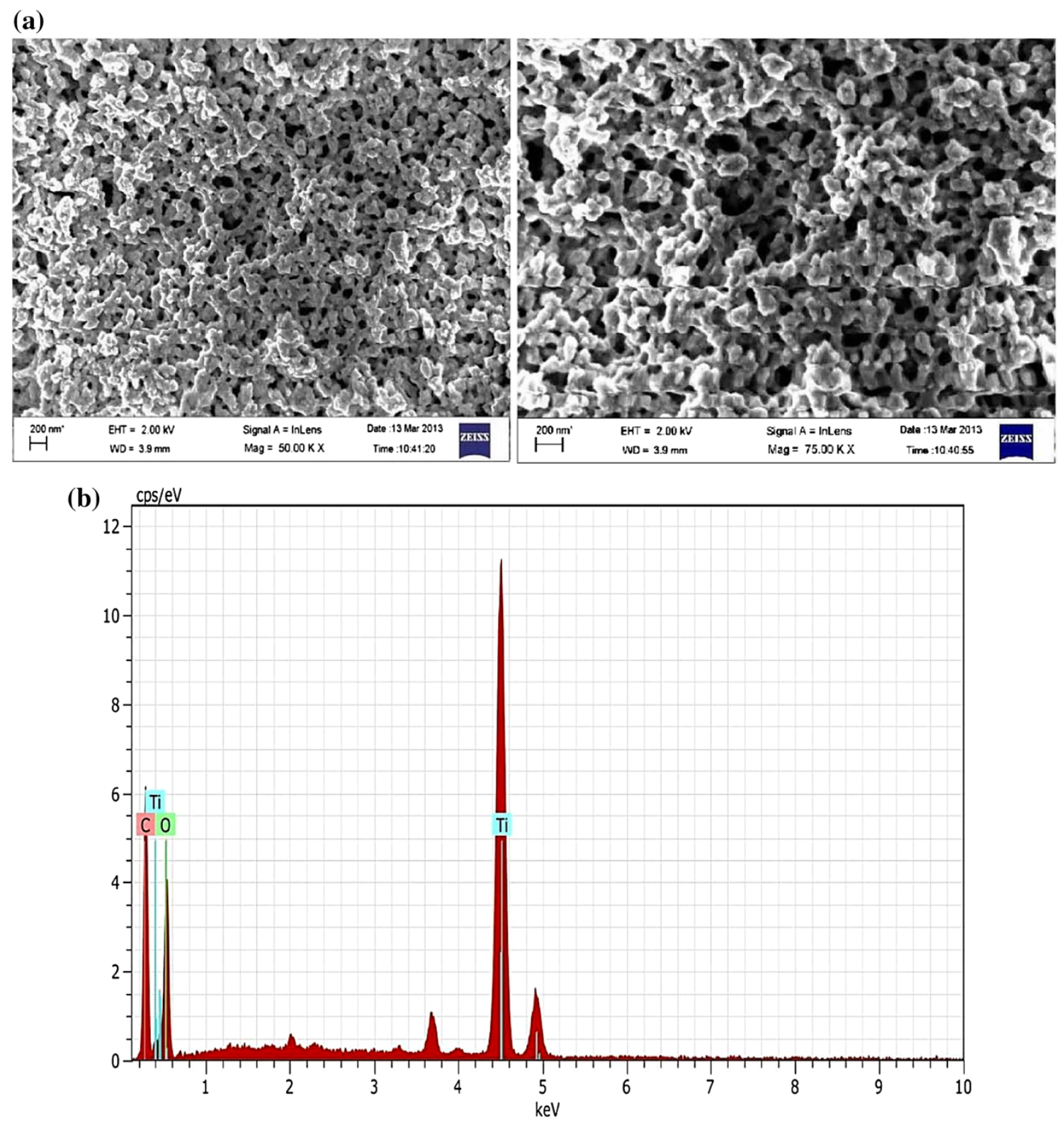

Fig. 2 a Field emission scanning electron microscopic studies; b energy-dispersive X-ray spectrum of titanium dioxide nanoparticles

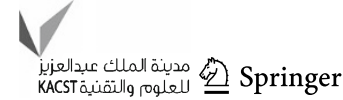


(a) Size Distribution by Intensity

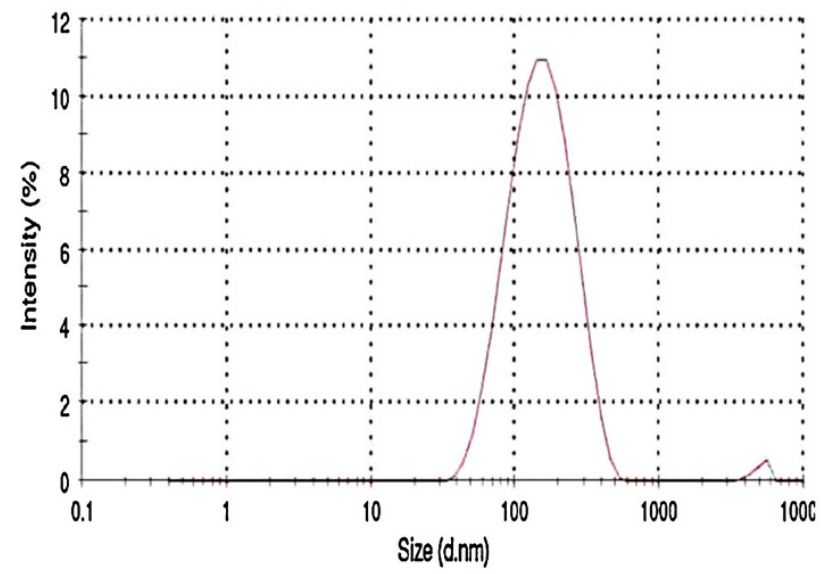

(b) Zeta Potential Distibution

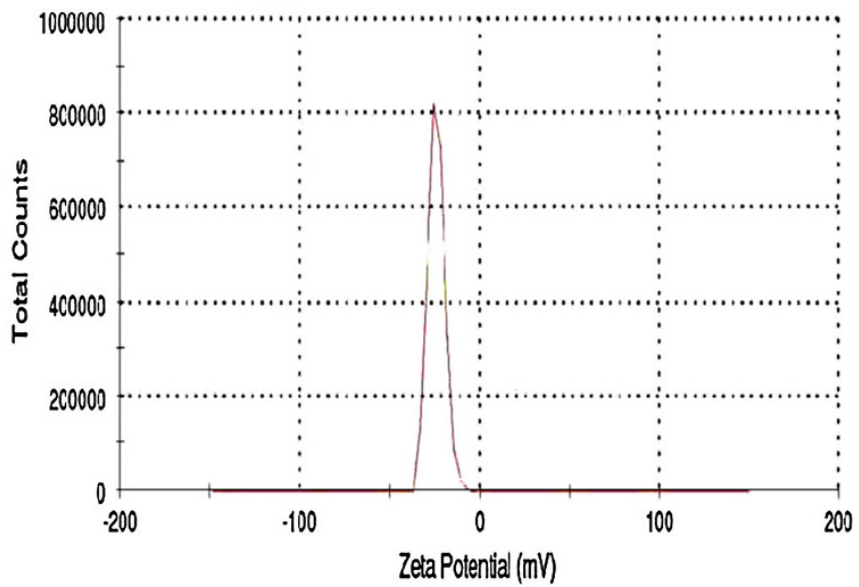

Fig. 3 DLS measurements a particle size distribution $(124 \mathrm{~nm})$; b zeta potential measurement $(-24 \mathrm{mV})$

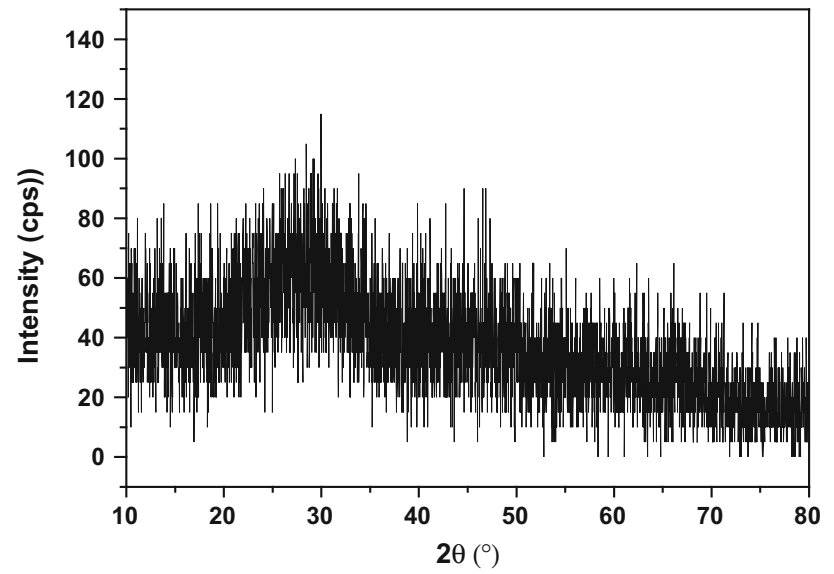

Fig. 4 XRD pattern of titanium dioxide nanoparticles

of fields, but limited evidence only available in the photocatalytic dye degradation experiment. To attain the abovementioned goal, we synthesized $A$. indica leafextract-mediated titanium dioxide nanoparticles. The $A$. indicia leaf-extract-mediated titanium dioxide nanoparticles were successfully synthesized by reducing $5 \mathrm{mM}$ titanium isopropoxide solution at $50{ }^{\circ} \mathrm{C}$ with $\mathrm{pH}$ 1.5. A maximum intensity of dark brown color titanium dioxide nanoparticles was observed after $5 \mathrm{~h}$ continuous stirring. The synthesized titanium dioxide nanoparticles were confirmed by comparing the color with control (A. indica leaf extract) (Fig. 1a). For the synthesized titanium dioxide nanoparticles, an excitation between 270-320 nm was confirmed by UV-visible spectrophotometry (Fig. 1a) (Patra et al. 2011). The UV-Vis spectra absorption peak illustrates that the synthesized titanium dioxide nanoparticles are polydispersed in nature (Sankar et al. 2014c).

The Fourier transform infrared (FT-IR) spectrum of green synthesized titanium dioxide nanoparticles is shown

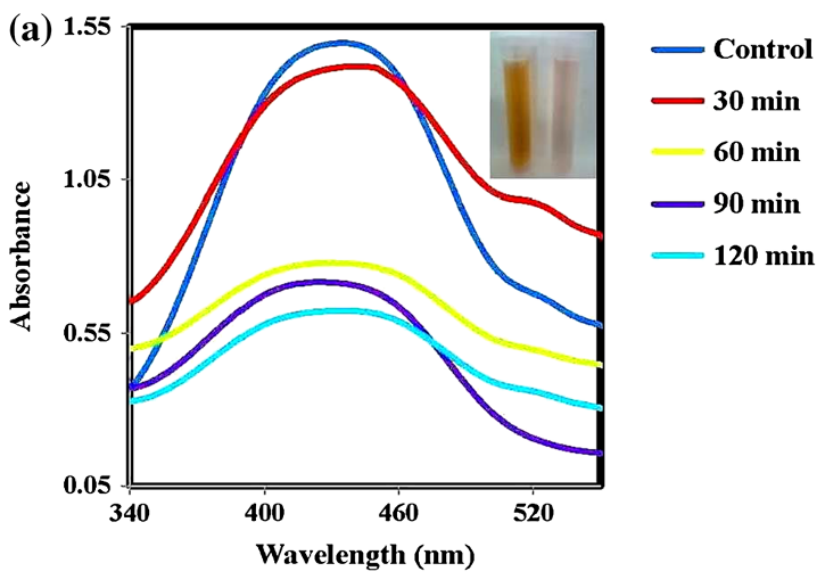

(b)

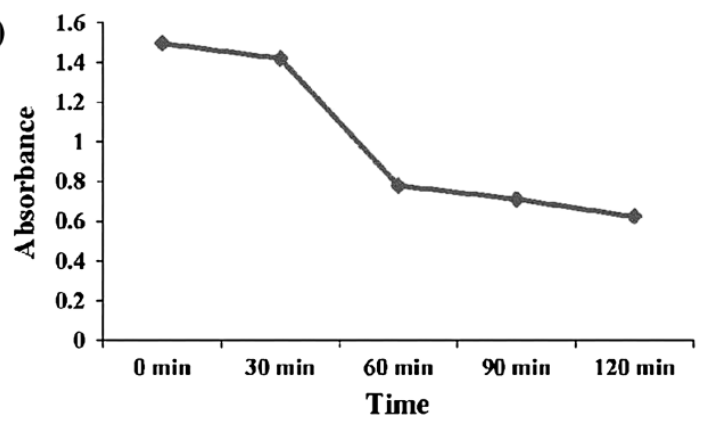

Fig. 5 UV-Vis absorption spectra a photocatalytic activity of colloidal titanium dioxide nanoparticles; $\mathbf{b}$ reduction of methyl red dye intensity at $437 \mathrm{~nm}$

in Fig. 1b. The FT-IR spectrum was recorded in the range of $4,000-400 \mathrm{~cm}^{-1}$. The frequency of bands related to amide $\mathrm{N}-\mathrm{H}$ stretching $\left(3,445 \mathrm{~cm}^{-1}\right)$, amide $\mathrm{C}=\mathrm{O}$ stretching $\left(1,640 \mathrm{~cm}^{-1}\right)$ and nitro $\mathrm{N}-\mathrm{O}$ bending $\left(1,395 \mathrm{~cm}^{-1}\right)$. The peaks absorbed at 758,593 and $447 \mathrm{~cm}^{-1}$ are contributions to $\mathrm{Ti}-\mathrm{O}$ stretching vibrations, an approving the formation of titanium dioxide nanoparticles (Chen et al. 2010). The 
green synthesized titanium dioxide nanoparticles morphological images were captured using field emission scanning electron microscope (FE-SEM). The A. indica leaf-extractmediated titanium dioxide nanoparticles are spherical in shape and interconnected with one another (Fig. 2a). The EDAX analysis results showed high percentage of elemental titanium and oxide peaks (Fig. 2b). Sedghi and Miankushki (2012) reported that the interconnected nanoparticles are predominantly used for electrochemical and biological purpose. Figure 3a reveals green synthesized titanium dioxide nanoparticle average particle size (hydrodynamic diameter) of $124 \mathrm{~nm}$. In our present study, a negative zeta potential of about $-24 \mathrm{mV}$ was observed (Fig. 3b). The high absolute value of zeta potential designates high electrical charge on the surface of the nanoparticles (Sankar et al. 2014b). XRD analysis patterns lack distinct diffraction peaks, suggesting that the $A$. indica leafextract-mediated titanium dioxide nanoparticles are amorphous in nature (Fig. 4).

The photocatalytic degradation activity of A. indica leafextract-mediated colloidal titanium dioxide nanoparticles against methyl red dye solution was exposed in Fig. 5a. An ideal absorbance peak of the methyl red dye solution was originated at $437 \mathrm{~nm}$ (Fig. 5b). In our present study result exhibited, increase in the incubation time of titanium dioxide nanoparticles with methyl red solution efficiently up regulates the dye degradation under bright sunlight (Kumar et al. 2013). The titanium dioxide nanoparticles' time-dependent treatment with methyl red dye solution decreases peak intensity was compared with control (methyl red solution) (Sankar et al. 2014a). The titanium dioxide nanoparticles act as an excellent photocatalytic agent, due to their strong oxidizing power, non-toxicity and long-term stability (Tayade et al. 2007). The size, charge and morphology of synthesized nanoparticles might influence the enriched photocatalytic degradation activity. The titanium dioxide nanoparticles have been a widespread selection of material in photocatalytic reactions, because of their affordable price, abundance and photostability property (Aprile et al. 2008). Our present study results confirmed that the A. indica leaf-extract-mediated colloidal titanium dioxide nanoparticles can act as a best representative for the treatment of color dyes.

\section{Conclusions}

In conclusion, we successfully synthesized A. indica leafextract-mediated titanium dioxide nanoparticles. The physico-chemical properties of ecofriendly synthesized titanium dioxide nanoparticles were confirmed by UV-Vis, FT-IR spectroscopy, FE-SEM with EDAX, DLS and XRD analyses. Furthermore, time-dependent treatment of green synthesized titanium dioxide nanoparticles powerfully degrades the industry toxic methyl red color dye solution. The A. indica leaf-extract-mediated titanium dioxide nanoparticles could be used as an effective photocatalyst toward the remediation of pollution.

Acknowledgments We are grateful to Department of Science and Technology (DST) for providing financial assistance to Mr. Renu Sankar through the INSPIRE Fellowship scheme. We extend our acknowledgement to the University Grant Commission (UGC), Science and Engineering Research Board (SERB) for their financial support. We also thank Department of Science and Technology-Fund for Improvement of S and T Infrastructure in Universities and Higher Educational Institutions (DST-FIST) for their infrastructure support to our department.

Open Access This article is distributed under the terms of the Creative Commons Attribution License which permits any use, distribution, and reproduction in any medium, provided the original author(s) and the source are credited.

\section{References}

Aprile C, Corma A, Garcia H (2008) Enhancement of the photocatalytic activity of $\mathrm{TiO}_{2}$ through spatial structuring and particle size control: from subnanometric to submillimetric length scale. Phys Chem Chem Phys 10:769-783

Chen L, Pang X, Yu G, Zhang J (2010) In-situ coating of MWNTs with sol-gel $\mathrm{TiO}_{2}$ nanoparticles. Adv Mat Lett 1:75-78

Daneshvar N, Salari D, Khataee AR (2003) Photocatalytic degradation of azo dye acid red 14 in water: investigation of the effect of operational parameters. J Photochem Photobiol A Chem 157:111-116

Habibi MH, Tangestananejad S, Yadollahi B (2001) Photocatalytic mineralisation of mercaptans as environmental pollutants in aquatic system using $\mathrm{TiO}_{2}$ suspension. Appl Catal B Environ 33:57-63

Kumar KM, Sinha M, Mandal BK, Ghosh AR, Kumar KS, Reddy PS (2012) Green synthesis of silver nanoparticles using Terminalia chebula extract at room temperature and their antimicrobial studies. Spectrochim Acta A 91:228-233

Kumar P, Govindaraju M, Senthamilselvi S, Premkumar K (2013) Photocatalytic degradation of methyl orange dye using silver (Ag) nanoparticles synthesized from Ulva lactuca. Colloid Surf B 103:658-661

Patra AK, Das SK, Bhaumik A (2011) Self-assembled mesoporous $\mathrm{TiO}_{2}$ spherical nanoparticles by a new templating pathway and its enhanced photoconductivity in the presence of an organic dye. J Mater Chem 21:3925-3930

Sankar R, Karthik A, Prabu A, Karthik S, Shivashangari KS, Ravikumar V (2013) Origanum vulgare mediated biosynthesis of silver nanoparticles for its antibacterial and anticancer activity. Colloid Surf B 108:80-84

Sankar R, Dhivya R, Shivashangari KS, Ravikumar V (2014a) Wound healing activity of Origanum vulgare engineered titanium dioxide nanoparticles in Wistar albino rats. J Mater Sci Mater Med 25:1701-1708

Sankar R, Manikandan P, Malarvizhi V, Fathima T, Shivashangari KS, Ravikumar V (2014b) Green synthesis of colloidal copper oxide nanoparticles using Carica papaya and its application in photocatalytic dye degradation. Spectrochim Acta A 121:746-750

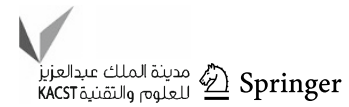


Sankar R, Maheswari R, Karthik S, Shivashangari KS, Ravikumar V (2014c) Anticancer activity of Ficus religiosa engineered copper oxide nanoparticles. Mater Sci Eng C Mater Biol Appl 44:234-239

Sedghi A, Miankushki HN (2012) Influence of $\mathrm{TiO}_{2}$ electrode properties on performance of dye-sensitized solar cells. Int $\mathbf{J}$ Electrochem Sci 7:12078-12089

Sulaiman GM, Mohammed WH, Marzoog TR, Al-Amiery AAA, Kadhum AAH, Mohamad AB (2013) Green synthesis, antimicrobial and cytotoxic effects of silver nanoparticles using
Eucalyptus chapmaniana leaves extract. Asian Pac J Trop Biomed 3:58-63

Syed A, Ahmad A (2013) Extracellular biosynthesis of CdTe quantum dots by the fungus Fusarium oxysporum and their anti-bacterial activity. Spectrochim Acta A 106:41-47

Tayade RJ, Surolia PK, Kulkarni RG, Jasr RV (2007) Photocatalytic degradation of dyes and organic contaminants in water using nanocrystalline anatase and rutile $\mathrm{TiO}$. Sci Tech Adv Mater 8:455-462 